\title{
Plectus - a stepping stone in embryonic cell lineage evolution of nematodes
}

\author{
Jens Schulze ${ }^{1}$, Wouter Houthoofd ${ }^{2}$, Jana Uenk ${ }^{1}$, Sandra Vangestel ${ }^{2}$ and Einhard Schierenberg ${ }^{* *}$
}

\begin{abstract}
Background: Recent studies have challenged the widespread view that the pattern of embryogenesis found in Caenorhabditis elegans (clade 9) is characteristic of nematodes in general. To understand this still largely unexplored landscape of developmental events, we set out to examine more distantly related nematodes in detail for temporospatial differences in pattern formation and cell specification. Members of the genus Plectus (clade 6) seem to be suitable candidates to show variety, with certain idiosyncratic features during early development and the convenient availability of cultivatable species.

Methods: The study was conducted using 4-D lineage analysis, 3-D modeling of developing embryos and laserinduced ablation of individual blastomeres.

Results: Detailed cell lineage studies of several Plectus species reveal that pattern formation and cell fate assignment differ markedly from C. elegans. Descendants of the first somatic founder cell S1 (AB) - but not the progeny of other founder cells - demonstrate extremely variable spatial arrangements illustrating that here distinct early cell-cell interactions between invariant partners, as found in C. elegans, cannot take place. Different from C. elegans, in Plectus alternative positional variations among early S1 blastomeres resulting in a 'situs inversus' pattern, nevertheless give rise to adults with normal left-right asymmetries. In addition, laser ablations of early blastomeres uncover inductions between variable cell partners.

Conclusions: Our results suggest that embryonic cell specification in Plectus is not correlated with cell lineage but with position. With this peculiarity, Plectus appears to occupy an intermediate position between basal nematodes displaying a variable early development and the C. elegans-like invariant pattern. We suggest that indeterminate pattern formation associated with late, position-dependent fate assignment represents a plesiomorphic character among nematodes predominant in certain basal clades but lost in derived clades. Thus, the behavior of S1 cells in Plectus can be considered an evolutionary relict in a transition phase between two different developmental strategies.
\end{abstract}

Keywords: Nematode, embryogenesis, cell lineage, cell specification, evolution, developmental system drift, Plectus, C. elegans

\section{Background}

The phylum Nematoda is considered a very ancient phylum reaching back into the Precambrian [1-3]. Wellpreserved fossils of nematodes from the early Devonian very much resemble recent basal representatives [4]. The number of extant nematode species is large with estimates ranging from tens of thousands to several millions [5-8]. Their adaptation to nearly all environmental

\footnotetext{
* Correspondence: e.schierenberg@uni-koeln.de

'Biocenter, University of Cologne, Zülpicher Strasse 47b, Cologne 50674, Germany

Full list of author information is available at the end of the article
}

conditions would predict a high plasticity on the morphological and physiological level. But the nematode body plan has remained uniform, despite a high genetic divergence and evolutionary variations in core developmental pathways even between close relatives [9-11].

With respect to embryonic development, the strong similarities in cleavage pattern between the classic study object Ascaris megalocephala (today: Parascaris equorum; $[12,13])$ and the modern model system Caenorhabditis elegans [14] led to the notion that this represents how nematodes generally develop. Extended studies in

\section{Biomed Central}


representatives from different branches of the phylogenetic tree made clear, however, that despite strong conservation of morphology, their embryogenesis is surprisingly variable [7,15-17] and hence the Ascaris/C. elegans pattern constitutes only one way to generate a worm.

Differences in early development among nematode species invalidate the long-standing notion formulated by von Baer [18] that during ontogeny first general characters are expressed that need to be conserved before evolutionary novelties are added.

Our recent analysis of basal nematodes (clades 1 and 2, according to the phylogenetic classification by [19] subdividing nematodes into 12 clades) revealed considerable differences from C. elegans, including lack of early asymmetric divisions associated with soma/germline separation, but also establishment of bilateral symmetry, spatial cell arrangements [17]. Thus, nematodes appear to be an attractive taxon to study evolution of development.

Representatives particularly amenable for comparative embryonic studies should meet several criteria: simple culture conditions, fast development and transparent eggs. So far, only free-living members of clades 6 to 12 seem to fulfill these criteria [17]. In search of candidates from these clades that may show developmental characteristics of both, basal nematodes (see above) and more derived species (clades 7 to 12; resembling the pattern found in Ascaris and C. elegans) representatives of the order Plectida (clade 6; [7]) appear to be promising candidates to search for such a combination of plesiomorphic and apomorphic characters. More than 70 different plectid species have been described [20] showing characteristic morphological features like setae (bristles) distributed over the entire body and unispiral amphids (chemosensory organs). The phylogenetic classification of plectid nematodes varied considerably in the past [21]. Several members of the genus Plectus can be cultured in the laboratory and embryos are transparent enough with sufficiently rapid development to allow detailed lineage analysis [22]. Among these, Plectus sambesii was found to have the fastest life cycle and highest reproductive rate under standard growth conditions. Therefore, most studies described here were performed on this representative, but other members of the genus were analyzed as well.

In the $C$. elegans embryo, cell specification requires reproducible spatial positioning of cells at specific milestone times to allow contacts and inductive signaling between neighboring blastomeres [23-25]. On the one hand, several plectid species were found to follow an early cleavage pattern similar to C. elegans, including the series of asymmetric cleavages going along with soma/germline separation. On other hand, plectids are clearly different in displaying an essentially perfect early bilateral symmetry within individual lineages and by initiating gastrulation prematurely with the immigration of an undivided gut founder cell [22].

In C. elegans, an invariant early left/right asymmetry is established in the 6-cell stage when two S1(AB) cell cousins on the left move anteriorly, while the corresponding pair on the right side moves posteriorly [26]. As a result, cells occupying equivalent positions in the left and right branches of the lineage tree adopt nonequivalent fates, and, vice versa, equivalent cell fates in the left and right half of the embryo are executed in a complex manner by cells of nonequivalent position in the lineage [14]. In the hatched worm, these early events result in a dextral handedness of organs. By experimentally inverting the left/right asymmetry of the four $\mathrm{AB}$ cells, a perfectly healthy 'situs inversus' (inverted left/right asymmetries) can be generated $[27,28]$. As the left/right shift of early blastomeres, which in C. elegans is a necessary prerequisite for the typical pattern of inductive interactions, was not observed in Plectus [22], we wondered whether cell specification follows different rules in this genus. Therefore, we set out to compare cell lineages, spatial pattern formation and cell fate assignment in Plectus with those of C. elegans and representatives of basal clades in order to better understand the evolution of developmental processes during embryogenesis of nematodes.

\section{Methods}

\section{Strains and culture}

The strains Acrobeloides maximus (DF5048), Acrobeloides nanus (ES501), Aphelenchus avenae (RGD103), Bursaphelenchus xylophilus (S10), Caenorhabditis brenneri (SB280), Caenorhabditis briggsae (AF16), Caenorhabditis elegans (N2), Choriorhabditis dudichi (SB122), Diploscapter sp. (JU359), Diploscapter coronatus (PDL0010), Halicephalobus gingivalis (JB128), Panagrolaimus sp. (JU765), Panagrolaimus superbus (DF5050), Plectus aquatilis (PDL0018), Plectus minimus (PDL0012), Plectus sambesii (ES601), Plectus sp. (ES603), Pristionchus pacificus (PS312), Protorhabditis sp. (DF5055), Protorhabditis sp. (JB122), Rhabditis belari (ES103), Rhabditis dolichura (ES101), Teratocephalus lirellus (JB049), Tylocephalus sp. (PDL1001) and Zeldia punctata (PDL0003) were cultured at $23^{\circ} \mathrm{C}$ on minimal agar plates essentially as described in [22]. Strains not isolated in our laboratory (ES) were obtained from Paul de Ley and Jim Baldwin, University of California at Riverside, USA; Marie-Anne Felix, Université Jacques Monod, Paris, France; Walter Sudhaus, Freie Universität Berlin, Germany; and Ralf Sommer, MPI for Developmental Biology, Tübingen, Germany. Data for Ascaris were taken from [12,13], for P. marina from [29], and for $\mathrm{H}$. gingivalis from [30]. Recordings of Meloidogyne incognita were obtained from Bartel Vanholme and Alejandro Calderón-Urrea, California State University, Fresno, USA. 


\section{Cell nomenclature and cell fate assignments}

Projection of C. elegans standard cell nomenclature $[14,31]$ onto other nematode species would imply similar cell fate patterns. Therefore, we apply neutral lineage names (S1to S4, somatic founder cells; P1 to P4, germline). In C. elegans, but not necessarily in other nematodes $\mathrm{S} 1=\mathrm{AB}, \mathrm{S} 2=\mathrm{EMS}, \mathrm{S} 3=\mathrm{C}, \mathrm{S} 4=\mathrm{D}$ [32]. For easier comparison between Plectus sambesii and C. elegans, we sometimes added for the former the standard names in parentheses.

Although we did not trace all embryonic divisions, we followed the behavior and localization of cells far enough to determine the tissues to which they contribute [17], in particular with respect to pharynx and hypodermis formation.

\section{4-D microscopy}

Early stage embryos collected from culture plates or cut out of gravid adults were mounted on slides carrying a thin 3\% agarose layer as a mechanical cushion [17]. Alternatively, gravid nematodes were dissected with a scalpel in a drop of distilled water on a poly-lysine-coated coverslip (0.01\%) with a drop of petroleum jelly as spacer in all four corners (modified after [33]). The coverslip was sealed with melted petroleum jelly. Embryonic development was examined with DIC optics using a 100x objective. Stacks of optical sections were digitally recorded at 30 to 60 second intervals and at $23^{\circ} \mathrm{C}$ with a
4-D microscope. 3-D tracing of cell behavior and generation of cell lineages were software-supported (Simi Biocell, Unterschleissheim, Germany), originally described in [34]. If not stated otherwise, development of at least seven embryos per species were analyzed.

\section{Cell ablation experiments}

1-cell embryos of P. sambesii were prepared for 4-D microscopy as mentioned above. For cell ablation, a Spectra-Physics Explorer $^{\text {TM }}$ Q-switched solid-state laser (Newport; Darmstadt, Germany) coupled to a Leica DMLB microscope (Leica; Wetzlar, Germany) via reflector optics was used. P1 and P2 cells were irradiated $3 \times 45$ seconds (at $50 \mathrm{~Hz}, 5 \mu \mathrm{J}$ ) with 30 -second intervals between irradiation periods. S3 cells were irradiated $3 \mathrm{x}$ 30 seconds (at $50 \mathrm{~Hz}, 2 \mu \mathrm{J}$ ) with 30 -second intervals.

\section{Cell extrusion experiments and cell culture}

Manipulated embryos were cultured in embryonic growth medium (EGM) adopted from [35] to support closure of the vitelline membrane [36] necessary for normal development. Perforated embryos continued to develop to several hundred cells. In contrast to C. elegans, in $P$. sambesii this medium does not support differentiation of isolated blastomeres outside the protective vitelline membrane. 2-cell embryos of P. sambesii were mounted on poly-lysine-coated slides, and distilled water was then replaced by EGM. A hole was burned into the
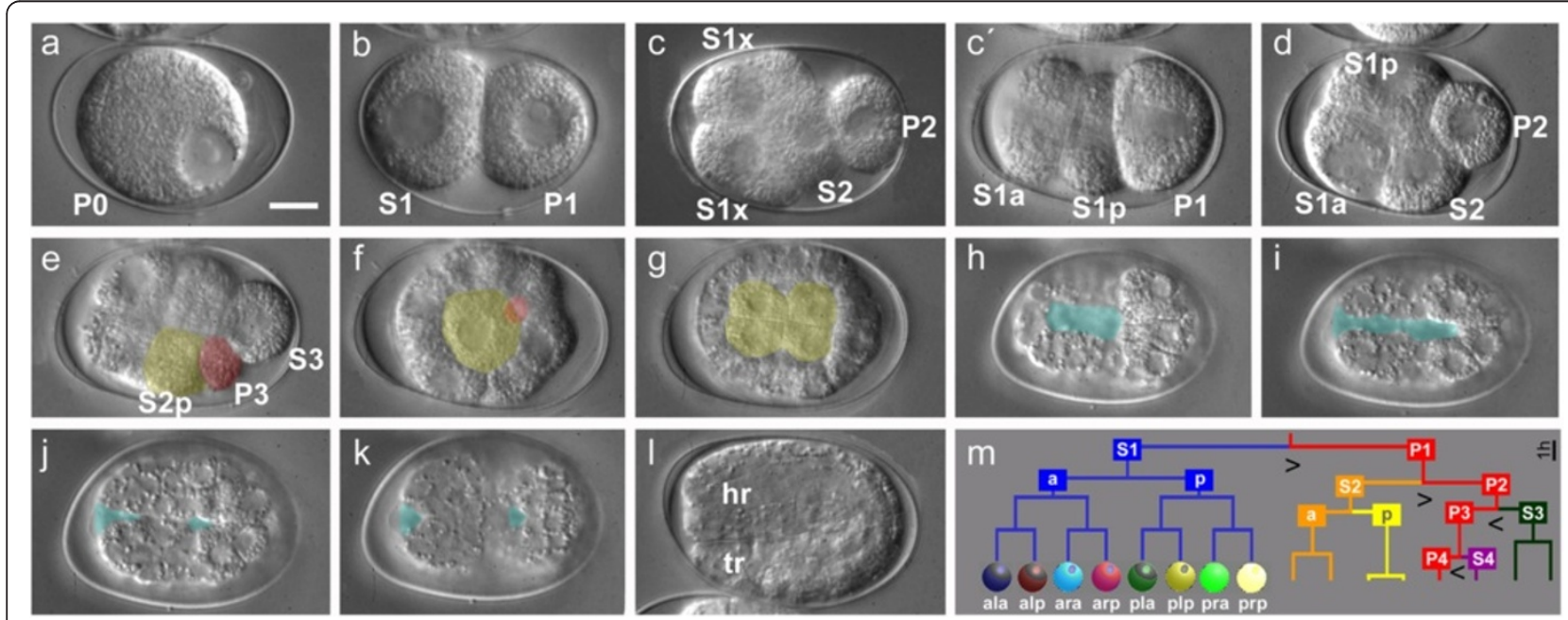

Figure 1 Embryogenesis in Plectus sambesii. (a) 1-cell stage (P0) with single pronucleus; (b) 2-cell stage with larger somatic founder cell S1 and smaller germline cell P1; (c) T-shaped 4-cell stage after transverse division of S1 and longitudinal division of P1; (c') rarely S1 divides with longitudinal spindle orientation; (d) diamond-shaped 4-cell stage after rearrangement of blastomeres; (e) 8-cell stage, with gut precursor S2p (yellow) and germline cell P3 (red); (f) approximately 16-cell stage, S2p (yellow) has migrated to the center but keeps contact with the primordial germ cell P4 on the surface (red; mostly out of focus); (g) embryo with 4-cell gut primordium (yellow); (h-k) formation and closure of blastopore (blue) on the ventral surface of the developing embryo; (I) twofold stage (early morphogenesis) with future head region (hr) top and tail region (tr) bottom; (m) early cell lineage, divisions of germline (P1 to P4; changing position indicates 'polarity reversal' as described for C. elegans; Schierenberg, 1987) generate somatic founder cells (S1 to S4), the eight descendants of S1 are color coded; S2 divides into pharynx/muscle precursor S2a (orange) and gut precursor S2p (yellow). Arrowheads indicate asymmetric divisions. DIC optics. Orientation: anterior, left. Bar, $10 \mu$ m. 
posterior part of the eggshell by pulsing repeatedly with the Spectra-Physics Explorer $^{\text {Ti }}$ Q-switched solid-state laser $(1 \mathrm{~Hz}, 60 \mu \mathrm{J})$. By using gentle pressure with a needle on the coverslip, the P2 cell was squeezed out of the eggshell and detached from the remainder of the embryo [37]. To visualize endocytotic activity as a marker for gut differentiation, EGM was supplemented with $0.25 \%$ Lucifer Yellow VS (LY, Mr 550, Sigma-Aldrich; Steinheim, Germany) and was allowed to penetrate the embryo by puncturing the eggshell with a laser microbeam [38]. After 15 minutes' incubation time, the LY medium was replaced by regular EGM. Localization of LY was visualized in terminal phenotypes by confocal microscopy.

\section{Results}

Cleavage pattern in the $\mathrm{P} 1$ lineage is conserved between $P$. sambesii and C. elegans

In $P$. sambesii, consecutive asymmetric cleavages of the germline (P0 to P3) along the main body axis result in the germ cell precursor P4 and somatic founder cells S1 to S4; (Figure 1; for cell nomenclature see Methods). Transverse orientation of the S1 and longitudinal orientation of the P1 cleavage spindles are like in C. elegans.
Thus, both species follow the T1-type of cleavage (Figure 1c; [17]). In rare cases $(<1 \%)$, longitudinal orientation of the cleavage spindle in S1 ( $\mathrm{n}>200$; Figure 1c') results in the I2-type. Both variants, however, result in a rhomboid 4-cell stage (Figure 1d) as found in C. elegans and many other nematodes [17] and lead to hatching juveniles. Our observations are in line with an earlier description of embryogenesis in P. sambesii [22] with respect to cell behavior of P1 descendants. Characteristic differences to C. elegans (Figure 2a-c) are found in the formation of bilateral symmetry in the S2a (MS) and S3 (C) lineages, where the first division generates two daughters in strictly left and right positions (Figure $2 \mathrm{~m}$ o) and gastrulation is initiated earlier with the immigration of the single gut founder S2p (E; Figure 1f) rather than its daughters.

We conclude from our study of a large number of $P$. sambesii embryos $(\mathrm{n}=73)$ that behavior of the P1 descendants is essentially invariant and similar to that of $C$. elegans $[14,33,34]$.

\section{Endoderm specification requires induction by $\mathrm{P} 2$}

In C. elegans, gut (E) differentiation depends on an inductive signal between P2 (germline) and S2 (EMS) in a

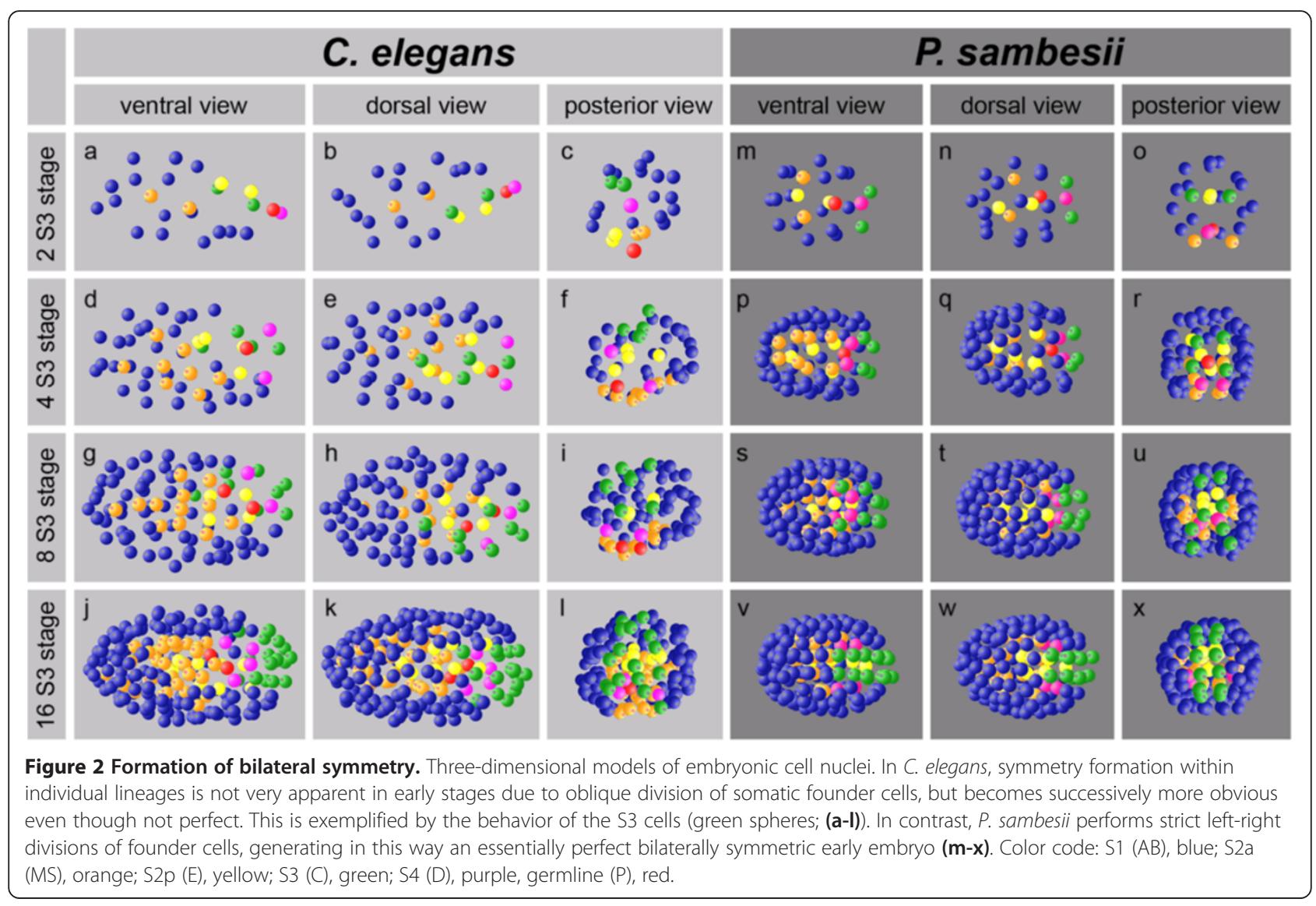


narrow time window in the early 4-cell embryo $[39,40]$. Because of the differences in gastrulation (see introduction) we wondered whether in $P$. sambesii gut-specific differentiation depends on an induction by the germline, as found in C. elegans.

We therefore ablated the P2 cell $(n=10$; Figure $3 f)$ as soon as it had separated from its sister cell S2 (EMS). In 9/10 cases we observed a typical early gastrulation with immigration of a single gut precursor (Figure 3g,h) and separation into a faster dividing S2a (MS) and a slower S2p (E; Figure 3l). In a single case $(1 / 10)$ we found a more or less synchronous sequence of divisions (Figure $3 \mathrm{~m}$ ). Visualization of gut differentiation was difficult as live markers like autofluorescence or formation of birefringent gut granules [41-43] are weak or absent.

Since in C. elegans, physical separation of P2 in time from the remainder of the embryo reliably prevents gut induction $[39,40]$, we removed the germline blastomere in the early 4-cell stage through a laser-induced hole in the eggshell ( $n=3$; Figure 3i). In these experiments, we added Lucifer Yellow to the extrusion medium, as this fluorescent marker dye is quickly and specifically taken up by gut precursor cells $[38,41]$. In test experiments, we had determined that such an accumulation takes place in Plectus as well. After early P2 extrusion $(n=3)$, division of S2a and $\mathrm{S} 2 \mathrm{p}$ was found to be essentially synchronous (Figure $3 \mathrm{~m}$ ) in contrast to normal development. In addition, although the typical early immigration of the gut precursor cell took place, there was no accumulation of fluorescent dye in the descendants of this cell (Figure 3j), indicating the absence of typical gut differentiation. To determine the time window of the assumed signaling, we then repeated this experiment in the late 6-cell stage after the division of the two $\mathrm{S} 1(\mathrm{AB})$ daughters $(\mathrm{n}=2)$. Under these conditions, cell cycle lengths of S2a (MS) and S2p (E) became different from each other (Figure 3l), normal internalization of S2p (E) took place, and fluorescent dye accumulated in the gut primordium (Figure $3 \mathrm{k}$ ).

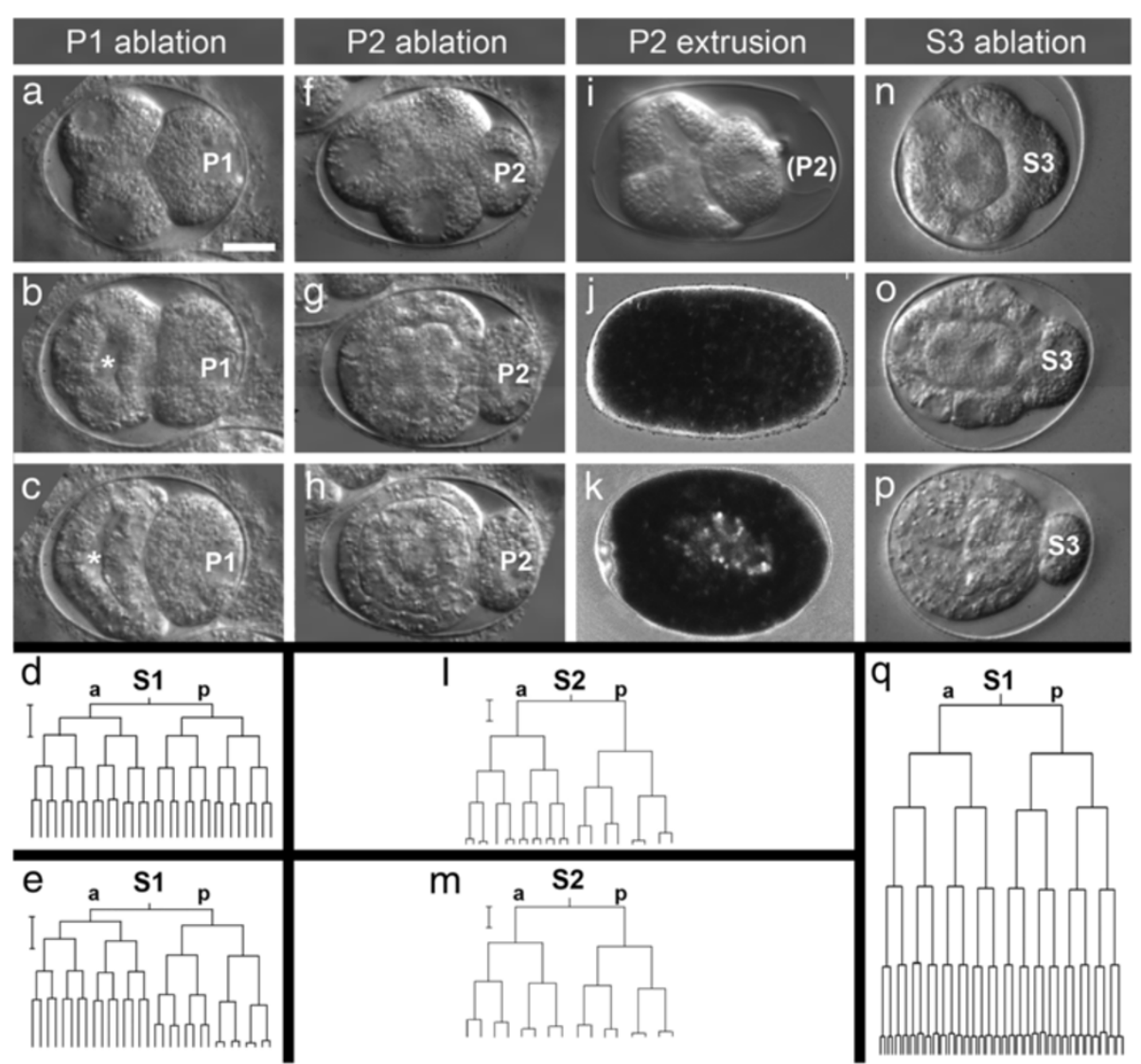

Figure 3 Cleavage behavior after cell elimination in P. sambesii. (a-c) After ablation of P1, the S1 descendants divide and form a blastocoel (marked with asterisk); (d, e) after ablation of P1, the S1 descendants can express normal synchronous cell cycles (d) or S1p descendants cleave asynchronously (e); (f-m) after early P2 ablation, S2 descendants lose their ability for asynchronous cell cycles (m) but after late ablation the normal cell cycle differences are expressed (I); (i-k) not after early (j) but after late extrusion of P2 (i), fluorescent marker dye accumulates in the gut primordium (k); (n-q) after early ablation of S3 (or P1/P2, see text), the typical retardation of cell cycles in three S1 descendants (see Figure 6) is lost (q). a-i, n-p: DIC optics; j, k, epifluorescence. Bar, $10 \mu \mathrm{m}$. 
Thus, our data show that, like in C. elegans, in P. sambesii: (i) P2 is necessary during the early phase of the S2p (E) cell cycle for proper endoderm specification and (ii) ablation of P2 is not sufficient to inhibit reliably its inductive signaling.

\section{High positional variation of $\mathrm{S} 1$ cells in $P$. sambesii unlike in C. elegans}

During embryonic development of $C$. elegans, but also $P$. sambesii (Figure 1; [22]) pattern formation among P1 descendants takes place in a simple and invariant fashion. In contrast, in C. elegans, spatial arrangement of blastomeres and fate designation in the S1 (AB) lineage, even though invariant, is rather complex [14] and requires specific cellcell interactions within narrow time windows [25,39]. Based on our observation that pattern formation in the S1 lineage of Plectus differs from C. elegans [22], we started a more detailed 4-D analysis of embryonic S1 lineages in $P$. sambesii, including an evaluation of cell-cell contacts, spatial variations thereof and their effect on cell fate assignment $(\mathrm{n}=73)$.

Hench et al. [33] reported recently that squeezing $C$. elegans embryos between microscope slide and coverslip can influence the spatial arrangement of blastomeres without necessarily compromising normal development. Therefore, we applied their minimal pressure-mounting technique for 30/73 embryos and for the remaining 43/ 73 embryos our standard procedure with an agarose pad as a cushion (see Methods). We found that the ratios of different spatial variants (described below) were not affected by the mounting technique applied.

We obtained the following results. First, minor deviations in cell cycle lengths and the sequence of cell divisions are within the same range as found in C. elegans [34] and therefore are not considered further here. Second, the descendants of the eight S1 sublineages (ala, alp, ara, arp, pla, plp, pra and prp; Figure $1 \mathrm{~m}$ ) form and preserve coherent well-defined regions as found in C. elegans $[33,34,44,45]$. Third, in contrast to the invariant embryonic development of C. elegans (called 'monomorphic' in the following), the spatial arrangement of these eight regions in $P$. sambesii is considerably variable (called 'polymorphic' in the following). The different regions do not intermingle, variants do not merge during ongoing development, and all of these are compatible with development to a fertile normal worm. They can be classified into distinct patterns ('polymorphs') as shown in Figure 4. Already in the 4 S1-cell stage, we can define four different variants by position of the S1 descendants (Types R, M1, M2 and L; Figure 4a, g, m, s). In both type $M$ variants, S1a and S1p (Figure $4 \mathrm{~g}, \mathrm{~m}$ ) divide with transverse spindle orientations, generating left and right descendants that keep their transverse positions. These types are rare $(n=3 / 73)$ and early differences between M1 and M2 polymorphs become obvious only in a posterior view (Figure $4 \mathrm{~g}^{*}, \mathrm{~m}^{*}$ ). Type $\mathrm{R}$ (Figure $4 \mathrm{a}, \mathrm{a}^{*}$ ) reveals a prominent shift of the two right S1 descendants to the posterior, while their siblings on the left side occupy more anterior positions. This type is the most abundant $(n=42 /$ 73). Members of type L (Figure $4 s, s^{*}$ ) behave the other way round such that left S1 descendants become located posterior relative to the right $\mathrm{S} 1$ cells. This type was found frequently $(\mathrm{n}=28 / 73)$.

During further development, three of the four above described polymorphs (Figure 4a, m, s) were found to split into two further variants due to minor differences in orientation of certain cleavage spindles in the 16 S1-cell stage (Figure 4d+d', v+v'; corresponding variant of Figure $4 \mathrm{p}$ not shown). Nevertheless, the general positions of the eight S1 cell clones relative to each other do not vary. While type $\mathrm{R}$ (a) and $\mathrm{L}$ (s) are frequent, the two variants of type $M\left(g^{*}, m^{*}\right)$ are rare. In type $L$, the variants $L R$ $(\mathrm{n}=16)$ and LL $(\mathrm{n}=12)$ occurred at about the same frequency, polymorph $\mathrm{RL}(\mathrm{n}=28)$ was twice as frequent as variant $R R(n=14)$. The rare types M2L $(n=1$; Figure $4 p-$ r) and M2R ( $n=1$; not shown) occurred with the same low frequency. A corresponding equivalent to the single M1L variant (Figure 4j-l) was not found in our collection.

\section{Are polymorphic patterns genetically inherited?}

As our studied P. sambesii strain reproduces parthenogenetically [46] and therefore genetic traits do not mix, we wondered whether the population is genetically diverse such that individuals with distinct developmental programs leading to one specific spatial pattern in their embryos coexist in fixed ratios.

To look for this, we recovered embryos whose early embryogenesis had been analyzed and allowed them to hatch and produce eggs. Samples consisting of multiple secondgeneration embryos from these single identified isolated mothers were noted and the eggs derived from each individual worm were studied to determine whether such eggs showed only the developmental pattern of their mother, or if one mother could produce different polymorphs. Among eggs from a mother of type M2R, we found $2 \times \mathrm{LR}, 2 \times \mathrm{LL}$, $1 \times$ RR, $4 \times$ RL; in eggs from a mother of type LR we found $1 \times$ LL, $2 \times$ RR, $5 \times$ RL; and in eggs from a mother of type RR, we found $4 \times$ LR, $1 \times$ LL, $1 \times$ RR. These data demonstrate that in $P$. sambesii the different embryonic patterns are not inherited as exclusive genetic traits. Despite the small sample size, it appears likely that a mother can produce any and all of the observed polymorphs.

\section{Differential behavior of S1 descendants depends on the P1 lineage}

Our findings demonstrate that in the polymorphs of $P$. sambesii, cell positions and therefore cell-cell contacts of S1 descendants vary. This raises the question whether cell fate assignment in the S1 lineage can take place in the 


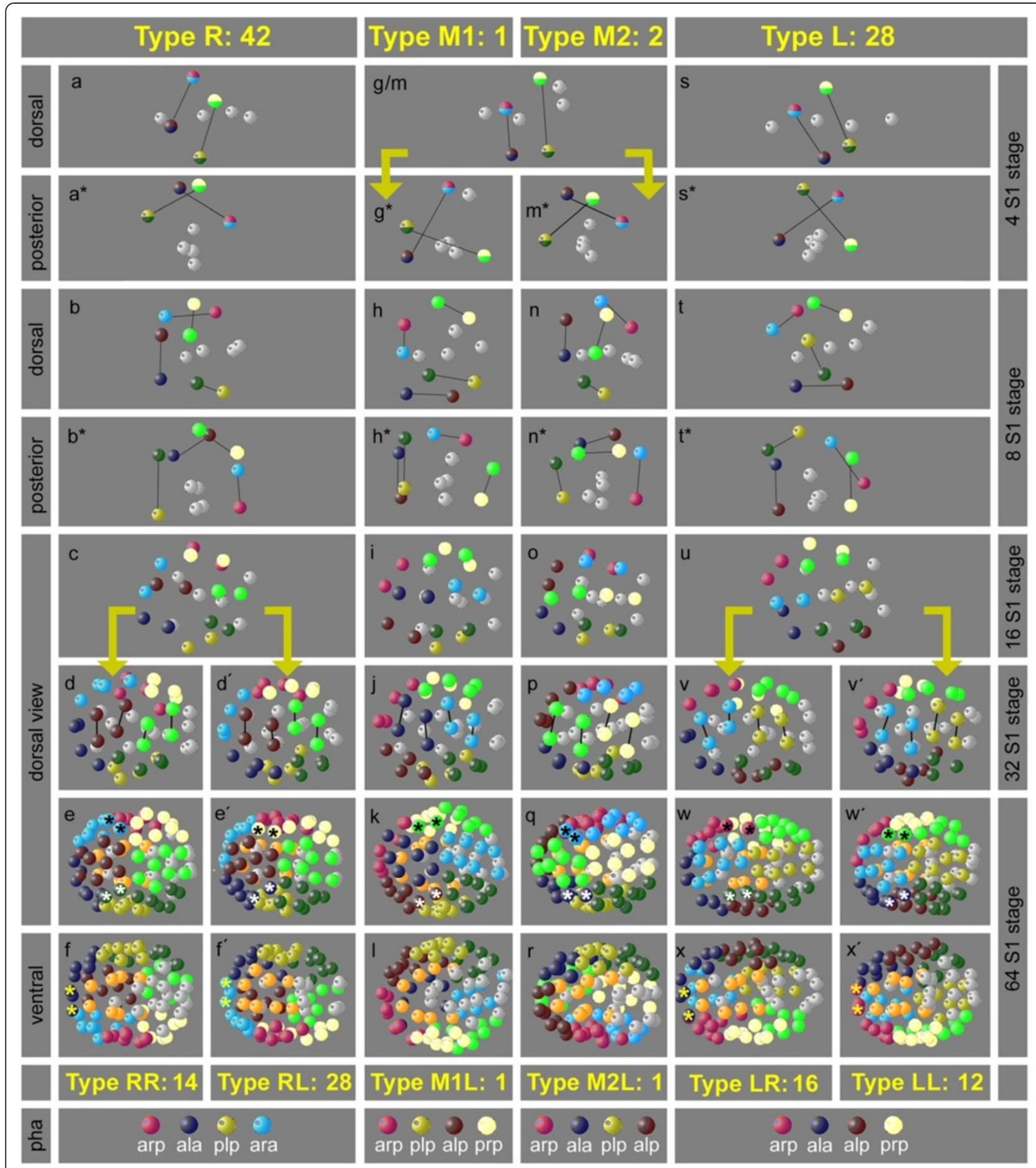

Figure 4 Variable arrangement of S1 descendants. Three-dimensional models of embryonic cell nuclei. With respect to the spatial arrangement of S1 blastomeres, four different cleavage types can be defined in the 8-cell stage (R, S1 blastomeres on the right side are positioned posterior to their left counterparts (a); L, S1 blastomeres on the left side are positioned posterior to their right counterparts (s); M1/M2, with respect to anterior/posterior $\mathrm{S} 1$ blastomeres on both sides occupy equivalent positions $(\mathbf{g} / \mathbf{m})$, but with respect to dorsal/ventral they occupy opposite positions $\left(\mathbf{g}^{*}, \mathbf{m}^{*}\right)$. With the division of $16 \mathrm{~S} 1$ cells, cleavage types $\mathrm{R}$ and $\mathrm{L}$ each reproducibly split into two further spatial variants $\left(\mathbf{d}+\mathbf{d}^{\prime} ; \mathbf{v}+\mathbf{v}^{\prime}\right)$ due to shifts of left and right S1 descendants relative to each other. To better visualize that in the 64 S1 cell stage, specific

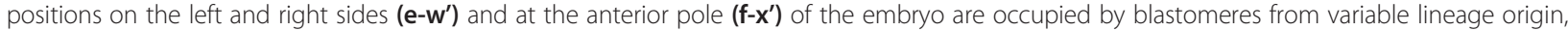
selected cells are marked with asterisks. Color code: members of the eight S1 descendants are marked as shown in Figure 1. Non-S1 cells are shown in light grey. 
same way as in the monomorphic $C$. elegans in which a strict correlation with lineage origin exists [14] and specific inductions between individual cells are essential [23-25].

As earlier studies on another nematode, Acrobeloides nanus (clade 11), had shown an altered cleavage and differentiation pattern of S1 descendants after elimination of P1 $[47,48]$, we performed the same test with P. sambesii. After ablation of P1 $(n=11$; Figure 3a), the S1 descendants divide in a symmetric fashion and form a prominent blastocoel (Figure $3 \mathrm{~b}, \mathrm{c}$ ). No events resembling gastrulation (as we had found in A. nanus $[47,48]$ and $R$. culicivorax [32]) were observed and the terminal phenotype did not show muscle contractions as found in experimental $A$. nanus embryos. However, with respect to cell cycle durations, manipulated Plectus embryos can be subdivided into two groups. In the first one $(n=5)$, descendants of S1 divided more or less synchronously (Figure 3d) but, in contrast to the untreated embryo, the typical later retardation in parts of the S1 lineage was not found (see hypodermis specification below). In the second group $(n=6)$, early descendants of S1p behaved atypically in that they expressed retarded and differential cell cycles (Figure 3e) while S1a descendants behaved normally. The retardation of S1 descendants (Figure 3e) resembles that in the manipulated $A$. nanus embryos; however, a separation into $\mathrm{AB}$ and EMS fates (indicated by muscle contractions and gastrulation events) was not found. As our observations indicate an influence of P1 or its descendants on the behavior of S1 cells, we investigated to what extent specification of pharyngeal cells depends on inductions as in C. elegans.

Variable cell contacts indicate differences in specification of pharyngeal cells. In the monomorphic C. elegans, the pharynx is generated in a complex polyclonal way by a fixed subset of S1 (ABara and alp) and S2a (MS) descendants. Pharynx precursor cells enter the body cavity from the ventral side during late gastrulation forming a cylinder anterior of the intestine [14]. Specification of S1-derived cells that contribute to the pharynx requires signaling from S2a descendants [25]. We analyzed the situation in P. sambesii in order to explore to what extent cell specification in the detected polymorphs may differ from C. elegans.

Our cell lineage analysis revealed that the pharynx in $P$. sambesii is composed polyclonally of $\mathrm{S} 1$ (AB) and S2a (MS) descendants comparable to C. elegans. Only in the former, the extending blastopore forms a prominent furrow (Figure $1 \mathrm{~h}-\mathrm{j}$ ) through which pharynx precursors (descendants of S2a) are translocated into the center of the embryo. Cells on the margin of this furrow contributing to the pharynx belong to four of the eight S1 clones. However, their lineage origin varies in the $\mathrm{R}, \mathrm{M} 1, \mathrm{M} 2$ and $\mathrm{L}$ polymorphs described above (Figure 4, bottom). Hence, we conclude that in P. sambesii, the origin of the S1 contribution to the pharynx is not related to cell lineage origin and therefore must depend on cell position.

The corollary that major differences must exist between C. elegans and P. sambesii with respect to cell specification is supported by the pattern of cell-cell contacts in the early embryo of the former. In the 12- and 26-cell stages, respectively, two inductions of single $A B$ descendants by MS (Figure 5a, e) lead to different fates of originally equipotent cells [25]. In contrast, in P. sambesii, S2a (MS) contacts in the 12-cell stage all four descendants of $\mathrm{S} 1 \mathrm{a}(\mathrm{ABa})$ in the polymorphs $\mathrm{R}, \mathrm{M} 1$ and $\mathrm{L}$ (Figure $5 \mathrm{~b}-\mathrm{d}$ ) and in three of these in the variant M2

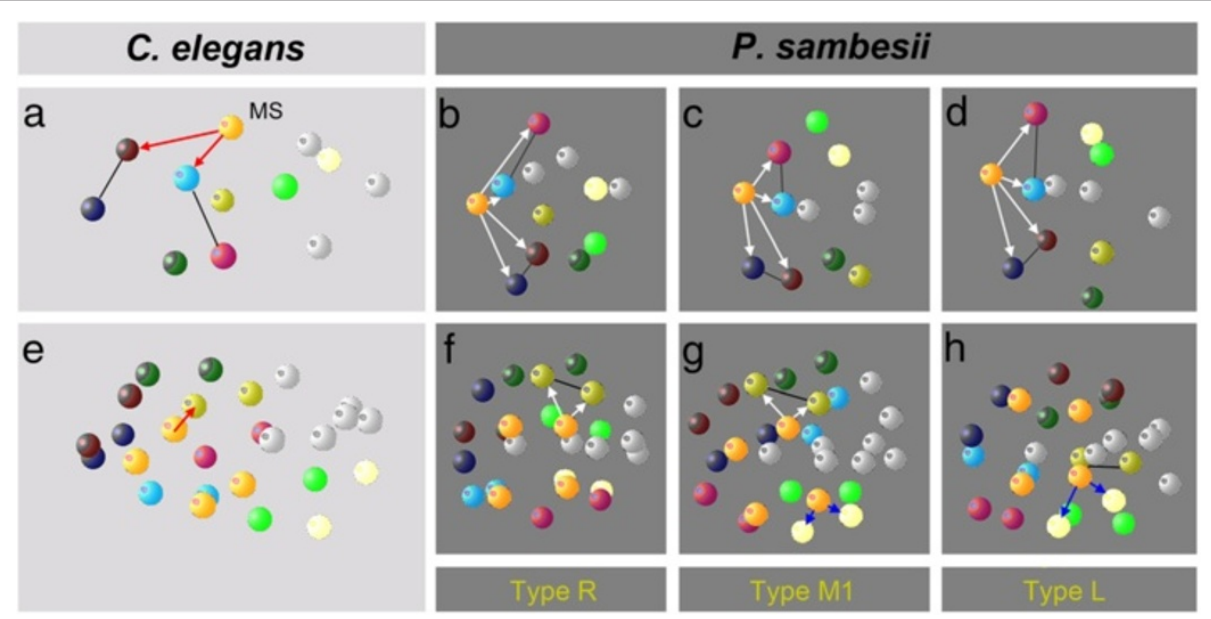

Figure $\mathbf{5}$ Cell contacts of S2a cells. Three-dimensional models of embryonic cell nuclei. In the 12-cell stage in C. elegans, S2a (MS) contacts and induces two of the four S1a descendants ((a); red arrows). In P. sambesii in the three different spatial variants, S2a (MS; orange) contacts all four S1a (ABa) descendants ((b-d); white arrows). In the 26-cell stage in C. elegans, MSap contacts and induces a single AB descendant ((e); red arrow). In P. sambesii either both ((f, $\mathbf{g})$; white arrows) or none (h) of S1 (AB) sister cells contacts the corresponding S2a (MSa) cell. Black bars connect selected sister cells. For nomenclature of spatial variants, see Figure 4. 


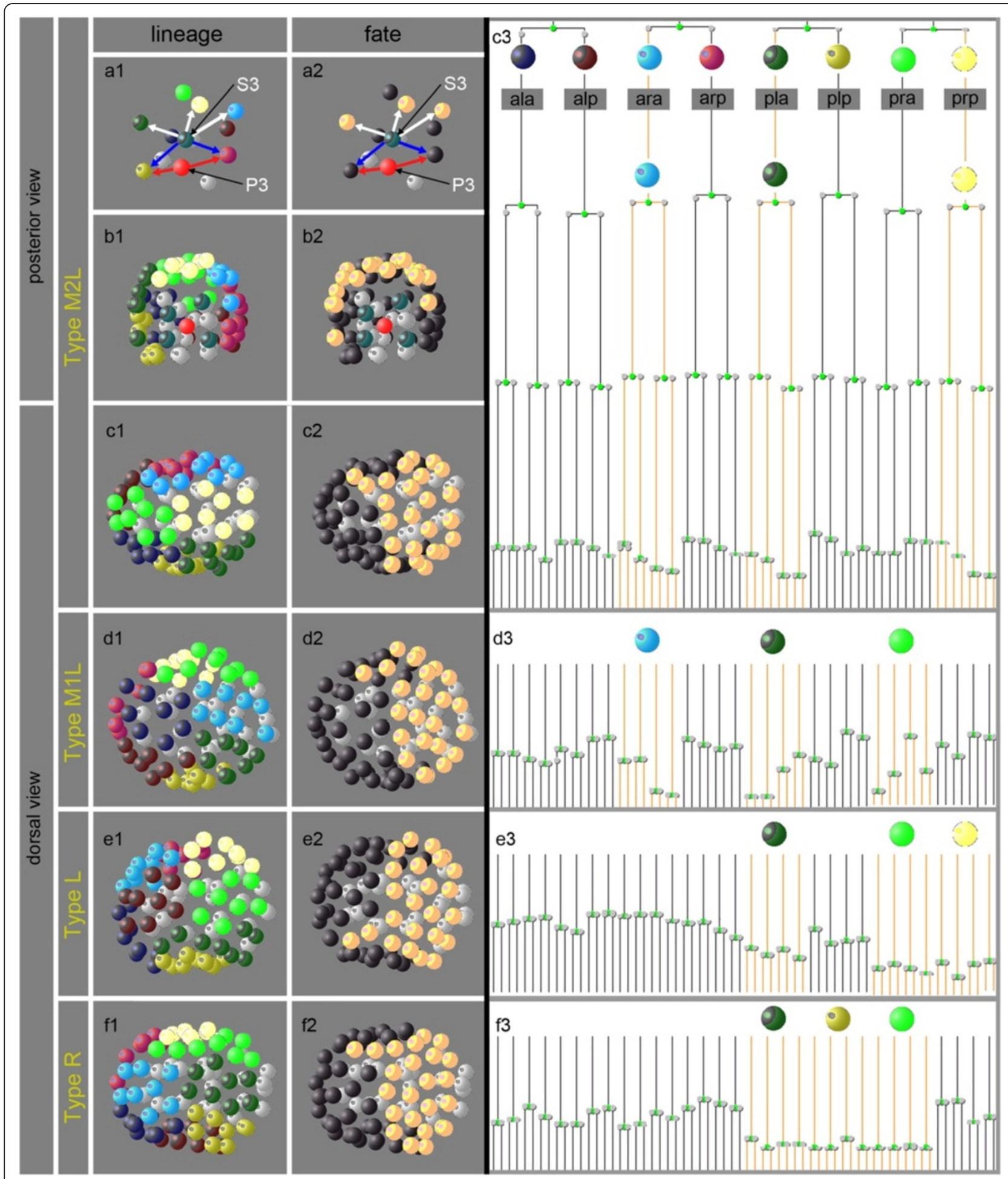

Figure 6 Different lineage, same fate. (a1-f2) Three-dimensional models of embryonic cell nuclei. In early Plectus embryos, five S1 descendants are contacted by S3 (white and blue arrows). Two of these are contacted in addition by P3 (red arrows). The three S1 blastomeres contacted exclusively by S3 (white arrows) generate descendants that occupy posterior dorsal and posterior lateral positions (b1, c1). These cells (light orange; remainder of $\mathrm{S} 1$, black) contribute to hypodermis (a2-c2) and later express retarded cell cycles (c3). In cleavage types $M 1 L, R$ and $L$, different sets of three S1 cells are exclusively contacted by S3 (not shown). Nevertheless, they all occupy the same positions as those in type M2L (d1-f1), contribute to posterior hypodermis (d2-f2) and express retarded cell cycles (d3-f3). For nomenclature of spatial variants, see Figure 4. 
(not shown). In the 26-cell stage either both sisters (Figure $5 \mathrm{f}, \mathrm{g}$ ) or none (Figure $5 \mathrm{~h}$ ) is touched by the corresponding S2a (MS) cell. Hence, cell contacts in Plectus are not compatible with a mechanism of cell specification as found in C. elegans.

With the observed embryonic polymorphs in mind (Figures 4,5 ) leading to differences in pharynx formation, we investigated how hypodermis is generated in $P$. sambesii.

\section{Specification of S1-derived hypodermis depends on cell position}

In C. elegans the hypodermis of the hatching juvenile is generated in a reproducible manner by members of the S1 (AB) and S3 (C) lineages [14].

Lineage analysis $(n=13)$ revealed that in $P$. sambesii, like in C. elegans, hypodermis is derived in a polyclonal manner from S1 (AB) and S3 (C) descendants. We found that in the embryonic polymorphs R, M1, M2 and L, descendants of $\mathrm{S} 1$ contributing to hypodermis always occupy the same spatial position (Figure 6b2-f2), which means that they have different lineage origin (Figure 6b1-f1). Only these blastomeres execute a retarded cell cycle rhythm compared to the other S1 descendants (Figure 6c3-f3). During ongoing development, they remain on the surface and some (positioned left and right of the dorsal midline) eventually interdigitate (not shown), typical for hypodermis formation in C. elegans [14] and R. culicivorax [16,32].

We revealed that in all observed polymorphs, only the S1 descendants in contact with S3 but not with P3 expressed a slower cell cycle (Figure 6a1, c3-f3). To test whether this was due to an induction, we performed a series of cell ablation experiments.

After irradiation of S3 $(n=2)$ or their ancestors P1 $(\mathrm{n}=3)$ and P2 $(\mathrm{n}=3)$, the typical retardation of posterior S1 descendants did not take place (Figure 3q) and no cells with hypodermis-like characteristics (see Methods) formed. In contrast, normal formation of hypodermis took place after ablation of S2a (data not shown). Hence, our results indicate that specification of hypodermis from variable posterior S1 cells takes place in a positiondependent manner and involves signaling by S3.

\section{Variable chirality during early cleavage but invariant handedness of adults indicates position-dependent cell specification}

Early cell arrangement in the prevailing polymorph R (Figure 4, left column; Figure 7c) resembles the invariant pattern found in C. elegans (Figure 7d; [26]).In previous experiments, Wood [27] generated an artificial type L via micromanipulation of early AB blastomeres (Figure 7e). In contrast to normal development (Figure $7 \mathrm{f}$ ), this variant gave rise to a 'situs inversus' with mirror-image orientation of organs (Figure $7 \mathrm{~g}$ ). To test whether any of the various polymorphs of $P$. sambesii developed abnormal handedness, we analyzed a large number of adults $(n>200)$ for the presence of situs inversus.

All specimens showed the standard left-right asymmetries (Figure $7 \mathrm{f}$ ) and not a single situs inversus was detected. This allows the conclusion that in the P. sambesii embryo, all of the identified polymorphic variants merge into a single adult phenotype. This finding gives further support to the conclusion drawn from the other observations reported above, that is, that in contrast to C. elegans, cell specification of S1 descendants depends on position in the embryo rather than position in the lineage tree.

\section{A shift from polymorphic to monomorphic embryogenesis supports a subdivision of the taxon Chromadorea}

As we had found early polymorphs in P. sambesii embryos associated with major differences in cell specification compared to the monomorphic C. elegans, we wondered how other members of clade 6 would behave. Analysis of three additional Plectus species and one

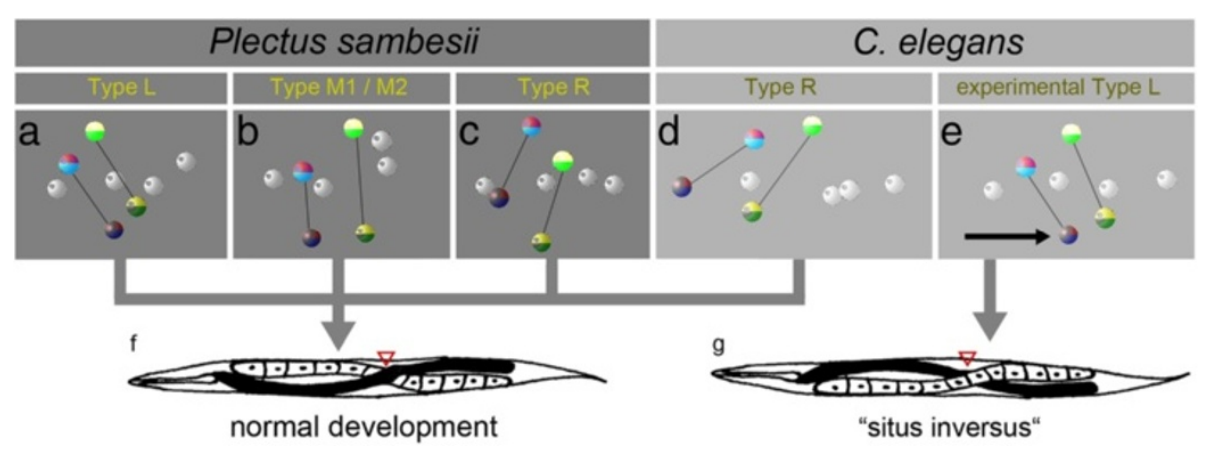

Figure 7 Position of early S1 (AB) descendants and handedness of adults. (a-e) Three-dimensional models of embryonic cell nuclei. In C. elegans, the four descendants of S1 form an early left/right asymmetry, (d) resulting in a specific arrangement of gut and gonad ((f), 'normal development'). Experimentally induced mirror-image arrangement of S1 descendants (e) results in a 'situs inversus' (g). In Plectus sambesii, positions of $\mathrm{S} 1$ cells differ considerably $(\mathrm{a}-\mathrm{c})$, but all variants develop into adults with normal handedness ( $\mathrm{f}$ ). For nomenclature of spatial variants, see Figure 4. 


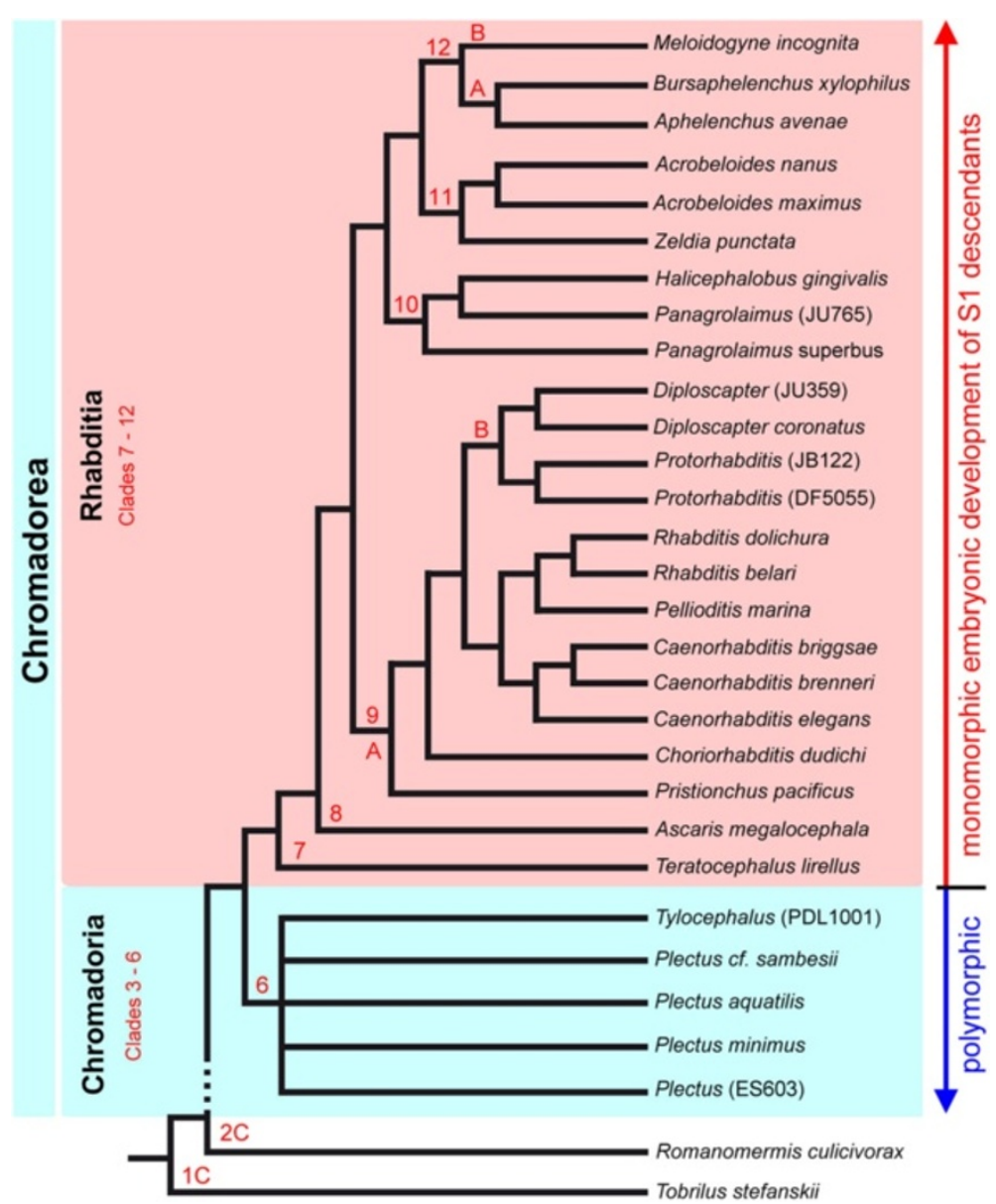

Figure 8 Phylogeny and development. Phylogenetic tree of nematodes ([19], modified [17]) comprising 12 clades. In the 23 studied members of clades 7 to 12, an invariant monomorphic development of S1 descendants was found, while all five representatives of clade 6 follow a variable polymorphic pattern. Based on these findings and additional data referenced in the text, a separation of 'Chromadorea' into 'Rhabditia' and 'Chromadoria' is supported.

Tylocephalus (each $\mathrm{n} \geq 7$; Figure 8) made clear that they all form variable spatial patterns of S1 descendants very much like those found in P. sambesii (data not shown).
Studies in other representatives of clades 8 and 9, for instance D. coronatus [49], P. marina [29] or C. briggsae [50], revealed that these are monomorphic
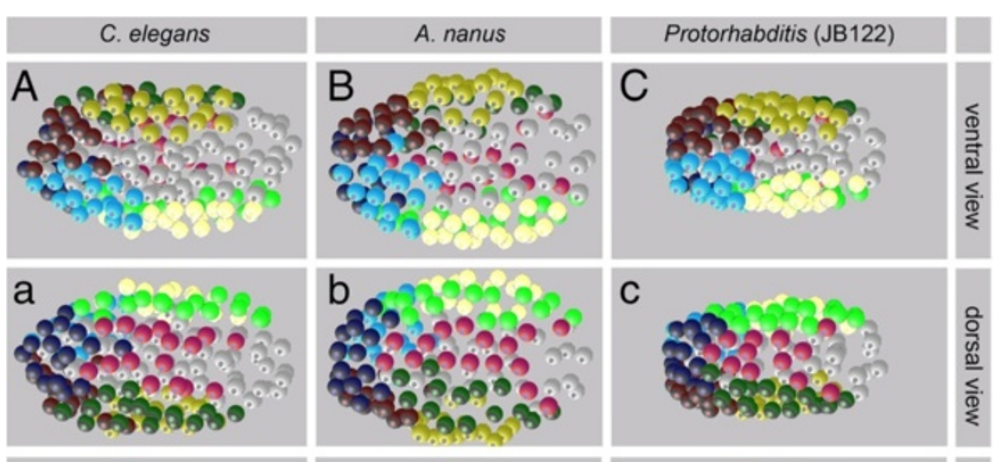

T1-type

T2-type

12-type

Figure 9 Cleavage type and cell pattern. Three-dimensional models of embryonic cell nuclei. A very similar arrangement of 64 S1 descendants is found in three nematode species with different early cleavage patterns (T1, T2, I2; see [17]). A-C, ventral view; a-c, dorsal view. Orientation: anterior, left. For color code, see Figure 1. 
and that development is very similar to that of $C$. elegans.

Since we had previously found four different early embryonic cleavage variants (T1, T2, I2 and I3; [17]) among species of clades 7 to 12 , we explored whether these show polymorphic behavior as described above. For this, we studied 22 additional members of these clades (each $\mathrm{n} \geq 7$; Figure 8) and found that embryos, despite distinct spatial variations during initial cleavage stages, all merge into the monomorphic C. elegans-like arrangement. Three examples, each representing a different early cleavage pattern [17], are shown in Figure 9.

The results from this comparative study support a subdivision of the taxon Chromadorea [21] into species with a Caenorhabditis-like development ('Rhabditia') and those following a Plectus-like development ('Chromadoria'). Such a separation had been suggested earlier based on morphological and developmental peculiarities in clades 3 to $6[7,22,51]$.

\section{Discussion}

\section{Nematodes of clade 6 appear to follow a different} developmental strategy

The study of embryogenesis in 28 nematode species from clades 6 to 12 (according to the phylogeny of [19]) representing different early cleavage patterns demonstrates a high diversity during early development and indicates major evolutionary modifications in the early cleavage and differentiation program of nematodes [17]. Surprisingly, embryogenesis in all 23 species of clades 7 to 12 merges into a common monomorphic (invariant) cell pattern prior to the onset of gastrulation comparable to that described for Ascaris $[12,13,52]$ and C. elegans $[14,31]$. The conserved spatial pattern following the initial variant phase can be best explained with the necessity for specific cell neighborhoods to allow inductions essential for proper specification of blastomeres [25]. Initially, founder cells need to be positioned in a specific order along the primary body axis $[14,17]$, then orientation of subsequent cleavages, steric constraints and secondary early cell rearrangements [49] result in a common monomorphic pattern.

However, our findings in Plectus sambesii and other representatives of clade 6 with their variable cell localization of S1 descendants appear to reflect a different developmental strategy. These species pass through a polymorphic development with a limited number of spatial variants, which nevertheless result in a single adult phenotype. This excludes a lineage-dependent early cell-specification as found in C. elegans $[14,25]$ and gives no indication for a global cell sorting as postulated by Schnabel et al. [45].

Early developmental similarities between plectids and selected species of clades 3 to 5 give some support for the assumption that these may share the same cell specification mechanisms $[7,53]$.

\section{Embryonic cell patterns and establishment of left/right asymmetry}

In many bilaterian animals, a left/right asymmetry of their internal organs has been found whereby one variant of asymmetry is predominant while the other ('situs inversus') is rare or even absent $[54,55]$. In a variety of nematode species, a preferred handedness was reported by zur Strassen [56] and explained with Mendelian inheritance. In Ascaris as well as in C. elegans, this asymmetry is established already in the 6-cell stage embryo when a shift of the left pair of $A B$ cell cousins relative to their counterpart on the right side takes place $[12,26,56]$. In all analyzed species of clades 7 to 12 (Figure 8 ) we observed only right-handed embryonic asymmetry resulting in a single corresponding adult phenotype. As an experimentally induced inverted embryonic asymmetry in C. elegans results in healthy, fertile 'situs-inversus' adults [27,28], the dominance of one variant is obviously not due to a developmental necessity but may have been fixed in the population because of steric or genetic constraints [54] or later benefits, like increased mating success as suggested by zur Strassen [56]. So far, only one nematode species has been described where a sinistral embryonic and adult phenotype is standard [57] but studies in other systems, such as snails and mice, indicate that a switch in handedness can be induced by a single mutation $[58,59]$. In contrast to the nematodes mentioned above, in Plectus sambesii we not only identified left and right but also rare intermediate embryonic patterns, which, however, all lead to the same dextral adult phenotype (Figures 4, 7). The unusual variation in the arrangement of coherent clonal regions exhibited by plectids with their implications on cell specification invokes the question of what changes must have taken place during evolution to come from a polymorphic, Plectus-like to a monomorphic, C. elegans-like mode of development and what the driving forces for this may have been.

\section{Evolution of cell lineage and cell specification - a scenario} In a recent publication [17], we sketched the gradual evolution from basal nematodes of the taxon Enoplida (clade 1) with no detectable early cell lineage [7] and delayed fixation of cell fate [60] via representatives with a partial early lineage as found in Tobrilus to Romanomermis (clade 2) with invariable development but predominantly monoclonal lineages. For a better understanding of how evolution proceeded to species with a complex polyclonal lineage as found in C. elegans [14] and all other studied representatives of clades 7 to $12[29,50,61]$ our findings in Plectus may be helpful.

Taking for granted that each taxon exhibits a combination of plesiomorphic and apomorphic characters, 
Plectus can be viewed as a stepping stone between basal nematodes (clades 1 to 2 ) where early specification is absent [60] and more derived representatives (clades 7 to 12; see Figure 8 ) with their invariant, polyclonal cell lineage. While in Plectus the descendants of P1 behave invariantly, this is markedly different in the progeny of S1 (AB). However, the variants in this lineage do not show a random distribution. The dextral-type RL is by far the most abundant (Figure 4) and this is just the one and only variant present in C. elegans, suggesting that, on an evolutionary time scale, Plectus may be on its way toward an invariant cleavage pattern as found in C. elegans.

We envision four important steps for such a transition to happen. (i) Starting from a nematode with a polymorphic monoclonal cell lineage (so far hypothetical), the introduction of position-dependent inductions initiates the beginning of a polyclonal lineage whose complexity will increase over time. (ii) The initially random distribution of polymorphic variants becomes biased, possibly by steric constraints like changes in shape or size of the eggshell or modified orientation of cleavages. The observed predominance of dextral variants in Plectus (Figure 4) may serve as an example for this. Compared to Plectus (Figure 1; [22]), the C. elegans embryo is more jammed inside the egg envelope, giving a possible explanation for an increase of situs inversus there after removal of the eggshell [62]. (iii) The essentially perfect bilateral symmetry as found in Romanomermis [16,32] and Plectus (Figures 2, 6; [22]) is broken and compensated by inductions [23-25] resulting in cells that perform equivalent fates in the left and right half of the embryo, although they occupy nonequivalent positions in the lineage tree. A variety of such examples can be found in the AB lineage of C. elegans [14]. (iv) The genetic fixation of cell fate via signaling of neighboring cells reduces tolerable variability and eventually leads to a monomorphic pattern. This goes along with an increasingly earlier specification of blastomeres. Elimination of gene function (see www.wormbase.org) and cell isolation experiments $[63,64]$ demonstrate the presence of a tightly woven network of early cell-cell interactions in C. elegans.

\section{Lineage versus position. How big is the difference between Plectus and C. elegans?}

The highly variable patterns of S1 cells in Plectus demonstrate the requirement of cell-cell interactions for proper cell specification. How fundamental then is the difference to $C$. elegans? The classic view of a purely cell-autonomous intrinsic cell specification in nematodes $[42,65]$ has been overcome with the discovery of early cell-cell interactions in C. elegans (for recent review, see [66]) which include S1 cells. A strong argument that in C. elegans fate assignment in the S1 lineage must also depend on extrinsic inductions beyond the cases revealed so far is supplied by the finding that an isolated
S1 cell generates only surviving descendants that contribute to the nervous system when cell-cell signaling is suppressed [45,67]. Promising candidates for further inductions in the S1 lineage include, for instance, anterior descendants with equivalent positions in the left and right half of the embryo but nonequivalent lineage affiliation, which nevertheless execute equivalent, bilateral symmetric fates [14]. Thus, the prominent difference between both species with respect to cell specification of S1 cells can be considered a gradual and not a fundamental one. The variable pattern formation going along with late, position-dependent fate assignment as found in Plectus appears to be a plesiomorphic character predominant in certain basal nematodes but lost in representatives of clades 7 to 12 . In this respect, Plectus and its kin may be in a transition phase between two different developmental strategies.

\section{Evolution of cell lineages and gene regulatory networks}

The driving forces for the establishment of a C. eleganslike cell lineage mechanism could be a faster developmental tempo due to an increased recourse to maternal gene products, an improved cost-efficiency of embryogenesis [68] or a better reliability of the cell-specification program, resulting in higher reproductive success. It has been argued that a monoclonal lineage allows a simple way for cell specification but requires extensive cell migrations, whereas a polyclonal lineage means more cell specification decisions but allows cells to be born where they are needed $[29,69]$. Both strategies have their advantages, but when rapid development and low cell numbers are an issue, a polyclonal invariant development should be superior. In addition, subdivision of a lineage into many small modules offers increased options for evolutionary fine-tuning. Thus, a polyclonal lineage offers more flexibility in the course of phylogeny, but less during ontogeny [32].

Studies on embryonic cell specification [10] vulva formation [11,70] and sex determination [71] in nematodes of the same clade as C. elegans revealed major modifications with respect to the underlying gene regulatory networks. Changes in the subcellular control mechanisms of development without corresponding reflections on the anatomical level, called developmental system drift [72], appear to be a common process in the animal kingdom, indicating that selective pressure is low on how to make an organism, but high on the functional capability of the final product. The cellular variations we report here together with previous studies [7,17,32,73] suggest that even more significant alterations of the molecular machinery can be expected when representatives of the whole phylum are compared. Initial support for this comes from genomic and gene expression data of various nematode species ([74,75]; our unpublished results). 
Nematode embryogenesis taking place in the protected encasement of a rigid egg envelope appears to be a fertile field for the exploration of alternative developmental pathways.

\section{Conclusions}

Our embryonic studies in nematodes of the genus Plectus reveal major differences with C. elegans. Most prominent is the variable positioning of S1 (AB) descendants, implying a position- rather than lineage-dependent mode of cell specification. With this peculiarity, Plectus appears to occupy an intermediate position between basal nematodes following an indeterminate early development and the C. elegans-like invariant pattern. Our results exemplify that developmental system drift not only allows large-scale modifications of gene regulatory pathways without impact on morphology but also of blastomere behavior during embryogenesis. While nematodes seem to be particularly suitable for studying the evolution of development due to their long history, ubiquitous distribution and amenability for detailed lineage analysis, the challenge for the future will be to correlate the alteration of cell behavior with the dynamics of the underlying molecular scaffolding.

\section{Abbreviations}

DSD: developmental system drift; EGM: embryonic growth medium.

\section{Competing interests}

The authors declare that they have no competing interests.

\section{Authors' contributions}

JS, WH and ES contributed to the conception and design of the study, all authors were involved in acquisition of data, its analysis and interpretation. $J S$ and ES drafted the manuscript and all authors read and approved the final version.

\section{Acknowledgements}

We are indebted to various colleagues for sharing strains (listed in Methods) and to Oleksandr Holovachov for identification of P. cf. sambesii. We appreciate the critical reading of the manuscript by Randy Cassada and Curtis Loer. JS was supported by the Deutsche Forschungsgemeinschaft (Schi 214/16-1); WH was supported by the Foundation of Scientific Research, Flanders (FWO, grant number 1.5.122.08 N).

\section{Author details}

'Biocenter, University of Cologne, Zülpicher Strasse 47b, Cologne 50674, Germany. ${ }^{2}$ Department of Biology, Ghent University, Ledeganckstraat 35, Ghent 9000, Belgium.

Received: 2 April 2012 Accepted: 24 May 2012

Published: 2 July 2012

\section{References}

1. Douzery EJ, Snell EA, Bapteste E, Delsuc F, Philippe H: The timing of eukaryotic evolution: does a relaxed molecular clock reconcile proteins and fossils? Proc Natl Acad Sci USA 2004, 101:15386-15391.

2. Blaxter M: Nematodes (Nematoda). In The time tree of life. Edited by Hedges SB, Kumar S. Oxford: Oxford University Press; 2009:247-250.

3. Poinar GO: The evolutionary history of nematodes: as revealed in stone, amber and mummies. Leiden: Brill; 2011.

4. Poinar G, Kerp H, Hass H: Palaeonema phyticum gen. n., sp n. (Nematoda: Palaeonematidae fam. n.), a Devonian nematode associated with early land plants. Nematology 2008, 10:9-14.
5. Meldal BH, Debenham NJ, De Ley P, De Ley IT, Vanfleteren JR, Vierstraete AR, Bert W, Borgonie G, Moens T, Tyler PA, Austen MC, Blaxter ML, Rogers AD, Lambshead PJ: An improved molecular phylogeny of the Nematoda with special emphasis on marine taxa. Mol Phylogenet Evol 2007, 42:622-636.

6. Lambshead PJD, Boucher G: Marine nematode deep-sea biodiversity - hyperdiverse or hype? J Biogeogr 2003, 30:475-485.

7. Malakhov W: Nematodes, Structure, Development, Classification and Phylogeny. Washington: Smithsonian Institution Press; 1994.

8. Poinar GO: The Natural History of Nematodes. New Jersey: Prentice Hall; 1983.

9. Kiontke K, Gavin NP, Raynes Y, Roehrig C, Piano F, Fitch DH: Caenorhabditis phylogeny predicts convergence of hermaphroditism and extensive intron loss. Proc Natl Acad Sci USA 2004, 101:9003-9008.

10. Lin KT, Broitman-Maduro G, Hung WW, Cervantes S, Maduro MF: Knockdown of SKN-1 and the Wnt effector TCF/POP-1 reveals differences in endomesoderm specification in C. briggsae as compared with C. elegans. Dev Biol 2009, 325:296-306.

11. Wang X, Sommer RJ: Antagonism of LIN-17/Frizzled and LIN-18/Ryk in nematode vulva induction reveals evolutionary alterations in core developmental pathways.PLoS Biol 2011. doi:10.1371/journal.pbio.1001110

12. Boveri T: Die Entwicklung von Ascaris megalocephala mit besonderer Rücksicht auf die Kernverhältnisse [in German]. In Festschrift für Carl von Kupffer. Jena: Gustav Fischer Verlag; 1899:383-430.

13. Müller H: Beitrag zur Embryonalentwicklung von Ascaris megalocephala [in German]. Zoologica 1903, 17:1-30.

14. Sulston JE, Schierenberg E, White JG, Thomson JN: The embryonic cell lineage of the nematode Caenorhabditis elegans. Dev Biol 1983, 100:64-119.

15. Schierenberg E: Unusual cleavage and gastrulation in a freshwater nematode: developmental and phylogenetic implications. Dev Genes Evol 2005, 215:103-108.

16. Schulze J, Schierenberg E: Cellular pattern formation, establishment of polarity and segregation of colored cytoplasm in embryos of the nematode Romanomermis culicivorax. Dev Biol 2008, 315:426-436.

17. Schulze J, Schierenberg E: Evolution of embryonic development in nematodes. EvoDevo 2011, 2:18.

18. von Baer KE: Über die Entwickelungsgeschichte der Thiere: Beobachtung und Reflektion. Königsberg: Bornträger; 1828.

19. Holterman $\mathrm{M}$, van der Wurff $\mathrm{A}$, van den Elsen $\mathrm{S}$, van Megen $\mathrm{H}$, Bongers $T$, Holovachov O, Bakker J, Helder J: Phylum-wide analysis of SSU rDNA reveals deep phylogenetic relationships among nematodes and accelerated evolution toward crown clades. Mol Biol Evol 2006, 23:1792-1800.

20. Holovachov O, De Ley P: Order Plectida. In Freshwater Nematodes: Ecology and Taxonomy. Edited by Abebe E, Traunspurger W, Andrássy I. Wallingford UK: CAB International; 2006:611-647.

21. De Ley P, Blaxter ML: Systematic Position and Phylogeny. In The Biology of Nematodes. Edited by Lee DL. London: Taylor and Francis; 2002:1-30.

22. Lahl V, Halama C, Schierenberg E: Comparative and experimental embryogenesis of Plectidae (Nematoda). Dev Genes Evol 2003, 213:18-27.

23. Eisenmann DM: Wnt signaling. In Wormbook. Edited by The C.elegans Research Community.; 2005. doi:10.1895/wormbook.1.7.1. http://www. wormbook.org.

24. Priess JR: Notch signaling in the C. elegans embryo. In WormBook. Edited by The C.elegans Research Community:; 2005. doi:10.1895/wormbook.1.4.1.

25. Schnabel H, Priess J: Specification of Cell Fates in the Early Embryo. In C elegans II. Edited by Riddle DL, Blumenthal T, Meyer BJ, Priess J. New York: Cold Spring Harbor Laboratory Press; 1997:361-382.

26. Schierenberg E, Carlson C, Sidio W: Cellular development of a nematode: 3-D computer reconstruction of living embryos. Roux's Arch Dev Biol 1984, 194:61-68.

27. Wood WB: Evidence from reversal of handedness in C. elegans embryos for early cell interactions determining cell fates. Nature 1991, 349:536-538.

28. Wood WB, Bergmann D, Florance A: Maternal effect of low temperature on handedness determination in C. elegans embryos. Dev Genet 1996, 19:222-230.

29. Houthoofd W, Jacobsen K, Mertens C, Vangestel S, Coomans A, Borgonie G: Embryonic cell lineage of the marine nematode Pellioditis marina. Dev Biol 2003, 258:57-69. 
30. Houthoofd W, Borgonie G: The embryonic cell lineage of the nematode Halicephalobus gingivalis (Nematoda: Cephalobina: Panagrolaimoidea). Nematology 2007, 9:573-584.

31. Deppe U, Schierenberg E, Cole T, Krieg C, Schmitt D, Yoder B, von Ehrenstein $\mathrm{G}$ : Cell lineages of the embryo of the nematode Caenorhabditis elegans. Proc Natl Acad Sci USA 1978, 75:376-380.

32. Schulze J, Schierenberg E: Embryogenesis of Romanomermis culicivorax: an alternative way to construct a nematode. Dev Bio/ 2009, 334:10-21.

33. Hench J, Henriksson J, Luppert M, Burglin TR: Spatio-temporal reference model of Caenorhabditis elegans embryogenesis with cell contact maps. Dev Biol 2009, 333:1-13.

34. Schnabel $\mathrm{R}$, Hutter $\mathrm{H}$, Moerman $\mathrm{D}$, Schnabel $\mathrm{H}$ : Assessing normal embryogenesis in Caenorhabditis elegans using a 4D microscope: variability of development and regional specification. Dev Biol 1997, 184:234-265.

35. Shelton CA, Bowerman B: Time-dependent responses to glp-1-mediated inductions in early C. elegans embryos. Development 1996, 122:2043-2050.

36. Schierenberg $E$, Junkersdorf $B$ : The role of eggshell and underlying vitelline membrane for normal pattern formation in the early $C$. elegans embryo. Dev Genes Evol 1992, 202:10-16.

37. Schierenberg E, Wood WB: Control of cell-cycle timing in early embryos of Caenorhabditis elegans. Dev Biol 1985, 107:337-354.

38. Bossinger $\mathrm{O}$, Schierenberg E: Early embryonic induction in $\mathrm{C}$. elegans can be inhibited with polysulfated hydrocarbon dyes. Dev Biol 1996, 176:17-21.

39. Goldstein B: Induction of gut in Caenorhabditis elegans embryos. Nature 1992, 357:255-257

40. Schierenberg E: Reversal of cellular polarity and early cell-cell interaction in the embryos of Caenorhabditis elegans. Dev Biol 1987, 122:452-463.

41. Bossinger O, Schierenberg E: Cell-cell communication in the embryo of Caenorhabditis elegans. Dev Biol 1992, 151:401-409.

42. Laufer JS, Bazzicalupo P, Wood WB: Segregation of developmental potential in early embryos of Caenorhabditis elegans. Cell 1980, 19:569-577

43. Babu P: Biochemical genetics of C. elegans. Mo/ Gen Genet 1974, 135:39-44

44. Bischoff M, Schnabel R: Global cell sorting is mediated by local cell-cell interactions in the C. elegans embryo. Dev Biol 2006, 294:432-444.

45. Schnabel R, Bischoff M, Hintze A, Schulz AK, Hejnol A, Meinhardt H, Hutter $\mathrm{H}$ : Global cell sorting in the C. elegans embryo defines a new mechanism for pattern formation. Dev Biol 2006, 294:418-431.

46. Lahl V, Sadler B, Schierenberg E: Egg development in parthenogenetic nematodes: variations in meiosis and axis formation. Int J Dev Biol 2006, 50:393-398.

47. Wiegner O, Schierenberg E: Specification of gut cell fate differs significantly between the nematodes Acrobeloides nanus and Caenorhabditis elegans. Dev Biol 1998, 204:3-14

48. Wiegner O, Schierenberg E: Regulative development in a nematode embryo: a hierarchy of cell fate transformations. Dev Biol 1999, 215:1-12

49. Lahl V, Schulze J, Schierenberg E: Differences in embryonic pattern formation between Caenorhabditis elegans and its close parthenogenetic relative Diploscapter coronatus. Int J Dev Biol 2009, 53:507-515.

50. Zhao Z, Boyle TJ, Bao Z, Murray Jl, Mericle B, Waterston RH: Comparative analysis of embryonic cell lineage between Caenorhabditis briggsae and Caenorhabditis elegans. Dev Biol 2008, 314:93-99.

51. Schierenberg E: Embryological variation during nematode development. In Wormbook. Edited by The C.elegans Research Community.; 2006. doi:10,1895/wormbook.1.55.1. http://www.wormbook.org.

52. Zur Strassen O: Embryonalentwicklung der Ascaris megalocephala [in German]. Arch Entwicklungsmech 1896, 3:27-105.

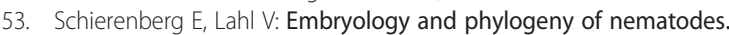
Nematol Monogr Persp 2004, 2:667-679.

54. Pohl C: Left-right patterning in the C. elegans embryo: Unique mechanisms and common principles. Commun Integr Biol 2011, 4:34-40.

55. Wood WB: Left-right asymmetry in animal development. Annu Rev Cell Dev Biol 1997, 13:53-82.

56. zur Strassen O: Der Erbgang der Nematoden-Asymmetrie [in German]. In Verh Dt Zool Gesellschaft. Willhelmshaven; 1951:77-81.

57. Felix MA, Sternberg PW, De Ley P: Sinistral nematode population. Nature 1996, 381:122

58. Okumura T, Utsuno H, Kuroda J, Gittenberger E, Asami T, Matsuno K: The development and evolution of left-right asymmetry in invertebrates: lessons from Drosophila and snails. Dev Dyn 2008, 237:3497-3515.
59. Yokoyama T, Copeland NG, Jenkins NA, Montgomery CA, Elder FF, Overbeek PA: Reversal of left-right asymmetry: a situs inversus mutation. Science 1993, 260:679-682

60. Voronov DA, Panchin YV: Cell lineage in marine nematode Enoplus brevis. Development 1998, 125:143-150.

61. Houthoofd W, Willems M, Jacobsen K, Coomans A, Borgonie G: The embryonic cell lineage of the nematode Rhabditophanes sp. Int J Dev Biol 2008, 52:963-967.

62. Wood WB: Handed asymmetry in nematodes. Semin Cell Dev Biol 1998, 9:53-60.

63. Arata Y, Lee JY, Goldstein B, Sawa H: Extracellular control of PAR protein localization during asymmetric cell division in the $C$. elegans embryo. Development 2010, 137:3337-3345.

64. Edgar LG, Goldstein B: Culture and manipulation of embryonic cells. Methods Cell Biol 2012, 107:151-175.

65. Boveri T: Die Potenzen der Ascaris Blastomeren bei abgeänderter Furchung. Zugleich ein Beitrag zur Frage qualitativ ungleicher

Chromosomenverteilung [in German]. In Festschrift für R Hertwig. Jena: Gustav Fischer Verlag; 1910:133-214.

66. Maduro MF: Cell fate specification in the C. elegans embryo. Dev Dyn 2010, 239:1315-1329.

67. Hutter H, Schnabel R: Establishment of left-right asymmetry in the Caenorhabditis elegans embryo: a multistep process involving a series of inductive events. Development 1995, 121:3417-3424.

68. Schierenberg E: Three sons of fortune: early embryogenesis, evolution and ecology of nematodes. Bioessays 2001, 23:841-847.

69. Stent GS: The role of cell lineage in development. Philos Trans $R$ Soc Lond B Biol Sci 1985, 312:3-19.

70. Felix MA, Barkoulas M: Robustness and flexibility in nematode vulva development. Trends Genet 2012, 28:185-195.

71. Haag ES: The evolution of nematode sex determination: $C$. elegans as a reference point for comparative biology. In WormBook. Edited by The C. elegans Research Community.; 2005. doi:10.1895/wormbook.1.120.1. http://www.wormbook.org

72. True JR, Haag ES: Developmental system drift and flexibility in evolutionary trajectories. Evol Dev 2001, 3:109-119.

73. Voronov DA: The embryonic development of Pontonema vulgare (Enoplida: Oncholaimidae) with a discussion of nematode phylogeny Russ J Nematol 1999, 7:105-114.

74. Kumar S, Schiffer PH, Blaxter M: 959 Nematode Genomes: a semantic wiki for coordinating sequencing projects. Nucleic Acids Res 2012, 40:D1295-D1300.

75. Sommer RJ, Streit A: Comparative genetics and genomics of nematodes: genome structure, development, and lifestyle. Annu Rev Genet 2011, 45:1-20.

doi:10.1186/2041-9139-3-13

Cite this article as: Schulze et al:: Plectus - a stepping stone in embryonic cell lineage evolution of nematodes. EvoDevo 2012 3:13.

\section{Submit your next manuscript to BioMed Central and take full advantage of:}

- Convenient online submission

- Thorough peer review

- No space constraints or color figure charges

- Immediate publication on acceptance

- Inclusion in PubMed, CAS, Scopus and Google Scholar

- Research which is freely available for redistribution 